\title{
Uncommon causes of postoperative chronic diarrhoea mimicking enterocolitis in Hirschsprung's disease: is there a role for digestive endoscopy?
}

\author{
A. Pini Prato $\cdot$ Enrico Felici $\cdot$ Valerio Gentilino $\cdot$ Camilla Giunta $\cdot$ Stefano Avanzini $\cdot$ \\ Girolamo Mattioli $\cdot$ Cristina Coccia $\cdot$ Arrigo Barabino $\cdot$ Paolo Gandullia $\cdot$ \\ Vincenzo Jasonni
}

Published online: 20 December 2007

(C) Springer-Verlag 2007

Erratum to: Pediatr Surg Int

DOI 10.1007/s00383-007-2071-y

The first element of the principal author's surname was misinterpreted as a second given name. His name should have been rendered as A. Pini Prato.

The online version of the original article can be found under doi:10.1007/s00383-007-2071-y.

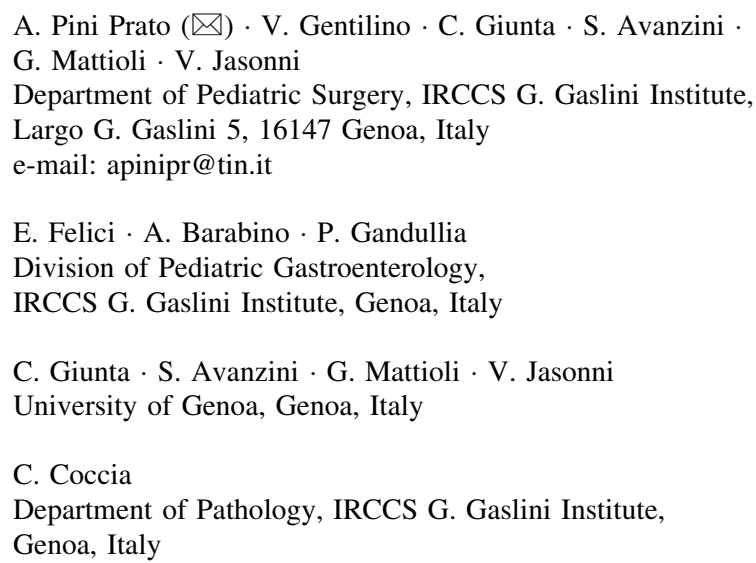

